\title{
Lazer e turismo: Visitas ao Observatório Abrahão de Moraes/IAG-USP (SP, Brasil)
}

\author{
Leisure and tourism: Visits to the Observatório Abrahão de Moraes/IAG- \\ USP (SP, Brazil)
}

\section{Ócio y turismo: Visitas al Observatório Abrahão de Moraes/IAG-USP (SP, Brasil)}

\author{
Geny Brillas Tomanik ${ }^{1}$ \\ Airton José Cavenaghi
}

\begin{abstract}
Resumo: Esta pesquisa exploratória, de caráter qualitativo, tem como objetivo analisar as atividades de lazer e de turismo promovidas pelo Observatório Abrahão de Moraes (OAM), situado na região de Valinhos e Vinhedo (São Paulo, Brasil), que o consideram um atrativo turístico. As suas principais atividades são direcionadas às pesquisas científicas em astronomia e astrobiologia. Além disso, abre as suas portas ao público local e turistas, funcionando como relevante difusor de conhecimento astronômico. Objetiva-se, ainda, investigar a relevância do equipamento para a comunidade local, a sua visibilidade, além da hospitalidade ali exercida. A metodologia utilizada foi a pesquisa bibliográfica exploratória com enfoque no lazer, turismo e hospitalidade, e também a coleta documental de dados nos sítios eletrônicos. A pesquisa qualitativa fundamenta-se em entrevistas pessoais entre membros selecionados da equipe do OAM; gestores locais das áreas de turismo e/ou cultura; residentes locais e visitantes. Conclui-se que o equipamento é um atrativo turístico e espaço de lazer com grande potencial a ser mais desenvolvido, em razão da sua reduzida visibilidade, e que o atendimento ao público é muito bem avaliado pelos visitantes.

Palavras-chave: Lazer; Turismo; Hospitalidade; Observatório Abrahão de Moraes/IAG-USP.
\end{abstract}

Abstract: This qualitative study aims to analyze the activities of leisure and tourism promoted by the astronomical observatory "Observatório Abrahão de Moraes" (OAM), located in the region of Valinhos and Vinhedo (São Paulo, Brazil), which is considered to be a touristic attraction. Its main activities are directed to scientific research in astronomy and astrobiology. It is also open for public and touristic visits working as a relevant diffuser of astronomical knowledge. The purpose is also to investigate the relevance of the equipment for the local community, its visibility, plus the hospitality exercised there. The methodology used was exploratory bibliographic research focused on leisure, tourism and hospitality, and also to collect documentary data in the websites. The qualitative research is based on personal interviews among selected members of OAM staff, local managers in the areas of tourism and/or culture, local residents and visitors.

1 Bacharel em Hotelaria, mestre em Hospitalidade junto à Universidade Anhembi Morumbi-SP. E-mail: gbtomanik@gmail.com. Este artigo é resultado das discussões da dissertação: Lazer e turismo: Observatório Abrahão de Moraes/IAG-USP, sob a orientação do Prof. Dr. Airton José Cavenaghi.

2 Doutor em História Social FFLCH-USP. Professor do Mestrado em Hospitalidade da Universidade Anhembi Morumbi (UAM-SP). E-mail: acavenaghi@gmail.com 
The conclusion is that the OAM is an attractive tourist and leisure site with an excellent evaluation from the visitors, however leaves a great potential for further development considering their reduced visibility.

Keywords: Leisure; Tourism; Hospitality; Astronomical Observatory Abrahão de Moraes /IAG-USP.

Resumen: Este estudio cualitativo tiene por finalidad analizar las actividades de ocio y turismo promovidas por el "Observatório Abrahão de Moraes" (OAM), situado en la región de Valinhos y Vinhedo (São Paulo, Brasil), considerado una atracción turística. Sus principales actividades están dirigidas a la investigación científica en astronomía y astrobiologia. Además de esto, abre sus puertas al público y a los turistas, funcionando como difusor de conocimiento astronómico relevante. Tiene por objeto también investigar la relevancia del observatorio Abrahão de Moraes para la comunidad local, su visibilidad, además de la hospitalidad ejercida allí. La metodología utilizada fue de tipo exploratorio, la búsqueda bibliográfica se centró en el ocio, el turismo y la hospitalidad, y también de datos documentales en los sitios web. La investigación cualitativa se basa en entrevistas personales entre los miembros seleccionados del personal de $O A M$, los administradores locales en las áreas de turismo y/o cultura, residentes locales y visitantes. Se concluye por tanto, que el equipamiento es un atractivo turístico y lugar de ocio con un gran potencial para desarrollarse aún más, debido a su visibilidad reducida, cuyas actividades son muy apreciadas por los visitantes.

Palabras clave: Ocio; Turismo; Hospitalidad; Observatório Abrahão de Moraes /IAG-USP.

\section{INTRODUÇÃO}

Neste universo em que os próprios astros são transitórios, a humanidade não é mais que um brevíssimo capítulo. Embora microscópica no tempo e no espaço, é ela quem conta essa grande história. (Damineli \& Steiner, 2010)

Fundado em 1972, o Observatório Abrahão de Moraes, também conhecido como OAM, é vinculado ao Instituto de Astronomia, Geofísica e Ciências Atmosféricas da Universidade de São Paulo (IAG-USP), e situa-se na divisa da região de Valinhos e Vinhedo/SP, onde está sendo instalado o primeiro laboratório de astrobiologia do país.

As suas principais atividades são direcionadas às pesquisas científicas em astronomia e astrobiologia. Além disso, desde 1998, o OAM abriu suas portas à visitação pública, previamente agendada, promovendo a difusão científica. A partir de 2008, foi considerado por ambas as municipalidades de Valinhos e Vinhedo um atrativo turístico regional, quando instituiu o evento "Noite com as estrelas".

Trata-se de um evento regular, mensal e gratuito, acessível a todas as faixas etárias e perfil socioeconômico. Nessas ocasiões, o público tem a oportunidade ímpar de realizar por meio de telescópios do OAM observações "in loco" de objetos celestes visíveis na data, além de fazer o reconhecimento do céu a olho nu. Quando as condições atmosféricas são desfavoráveis às observações astronômicas, estas são substituídas por palestras, elucidações interativas e visitas à parte da infraestrutura do observatório.

Nessas visitas monitoradas no espaço do OAM há uma dinâmica flexível, ou seja, a interação entre visitantes e anfitriões, onde são estabelecidas relações de hospitalidade, ou seja, para Montandon (2011, p. 1303) "[...] as visitas fazem parte dos lugares da memória" e é nesta 
forma de lembrança que a hospitalidade se manifesta.

Tendo em vista tais considerações, decidiu-se investigar o lazer e o turismo promovidos pelo Observatório Abrahão de Moraes (OAM), buscando analisar tanto a sua relevância para o turismo regional e a sua visibilidade junto à população local, quanto à hospitalidade ali exercida. Este artigo aborda inicialmente os observatórios astronômicos como atrativos turístico, com destaque para o observatório pesquisado.

\section{OBSERVATÓRIOS ASTRONÔMICOS E O OAM COMO ATRATIVOS TURÍSTICOS}

Um observatório astronômico é o local apropriado, dotado de equipamentos e infraestrutura adequados, com a finalidade de coletar dados e produzir informações para a pesquisa científica, ou seja, é o lugar onde se constrói a base do conhecimento astronômico (Teixeira, 2009).

E ainda, conforme Linhares (2011), observatórios astronômicos são locais destinados à pesquisa científica, ao ensino, à divulgação e à prática da astronomia amadora, ou ainda, de acordo com Mourão (1994), um observatório é um conjunto de instalações destinadas à observação dos fenômenos naturais (celestes, atmosféricos, geológicos ou magnéticos).

Desta forma, observatórios podem destinar-se exclusivamente às pesquisas científicas ou ao atendimento público, ou mesmo, ambos simultaneamente. Essas atividades junto ao público é uma forma de divulgação e de ensino não-formal de noções sobre astronomia nesses espaços (Langhi \& Nardi, 2009; Linhares, 2011).

De acordo com Linhares (2011), os mais antigos observatórios astronômicos foram os préhistóricos - conhecidos como observatórios arqueoastronômicos -, a exemplo de Stonehenge (Figura 1), na Inglaterra, Machu Pichu e Cusco, no Peru, entre outros, com características distintas dos equipamentos contemporâneos, pois utilizavam instrumentos bastante precários.

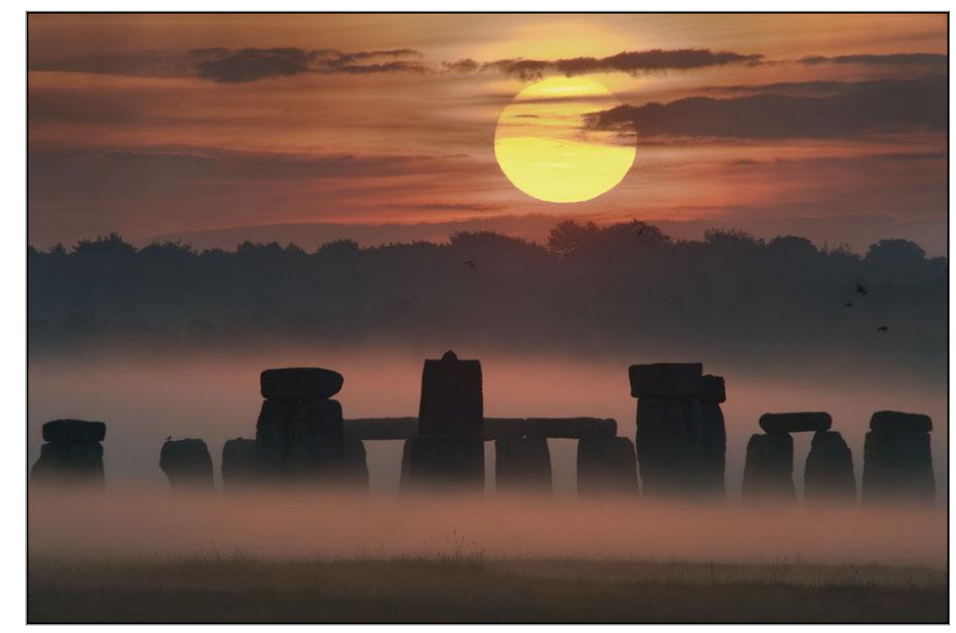

Figura 1. Amanhecer do solstício em Stonehenge ${ }^{3}$

\footnotetext{
${ }^{3}$ Fonte: Alexander (NASA, 2008). Recuperado de http://apod.nasa.gov/apod/ap100621.html.
} 
Essas edificações, algumas em ruína, algumas declaradas como patrimônio cultural da humanidade pela UNESCO, são atrativos turísticos, conforme corrobora San Blas (Starlight, 2007, p. 26, tradução livre):

Em nossos dias, o patrimônio cultural associado à astronomia também constitui a motivação de muitos viajantes. Já são muitos lugares e destinos consolidados quanto ao patrimônio relacionados à astronomia, incluindo a arqueoastronomia, um excelente exemplo de atração turística.

Da mesma forma, observatórios contemporâneos que disponibilizam visitações públicas também constituem atrativos turísticos, atraindo milhares de visitantes pelo mundo, que geralmente tem a oportunidade peculiar de realizar observações astronômicas in loco, como por exemplo, Mauna Kea Observatories (Figura 2), no Havaí, e no Brasil, o Observatório Abrahão de Moraes (OAM), entre tantos outros.

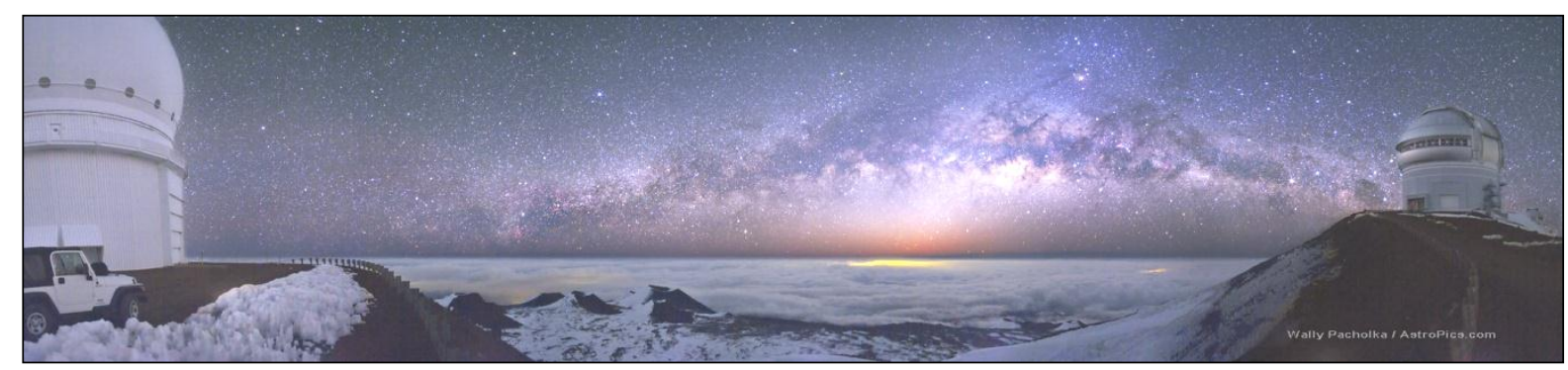

Figura 2. Mauna Kea Milky Way Panorama ${ }^{4}$

Na Figura 3, nota-se que a partir de 2008, ano em que o OAM foi reconhecido como atrativo turístico pelas prefeituras municipais de Valinhos e Vinhedo, houve um expressivo crescimento de atendimento ao público, motivado pela instituição do evento "Noite com as Estrelas", ou seja, a partir de 2008 as visitas públicas ao observatório poderiam ser também noturnas e regularmente, com atendimento a um público maior.

Além disso, o Observatório Abrahão de Moraes em 2008 e 2009 foi incluído no "Roteiro Turístico Cultural" das Festas da Uva de Vinhedo e do Figo de Valinhos, quando recebeu inúmeros visitantes, inclusive turistas, cujo passeio era constituído de visita ao Mosteiro de São Bento e, finalmente ao OAM, pois ambos localizam-se à mesma "Rua do Observatório".

As observações astronômicas in loco sofrem influências das condições climáticas, tanto para a pesquisa científica, bem como aquelas realizadas pelos visitantes, gerando flutuações no número de visitantes. O decréscimo do número de visitantes ao OAM em 2011 deveu-se às fortes intempéries nos primeiros meses do ano, que inclusive provocaram repetidas enchentes na região. Desta forma, o evento "Noite com as Estrelas" foi suspenso temporariamente por aproximadamente três meses, e restabelecido apenas a partir de março de 2011.

\footnotetext{
${ }^{4}$ Panorama da Via Láctea junto aos observatórios de Mauna Kea. Fonte: Pacholka (NASA, 2009). Recuperado de http://apod.nasa.gov/apod/ap090219.htm.
} 


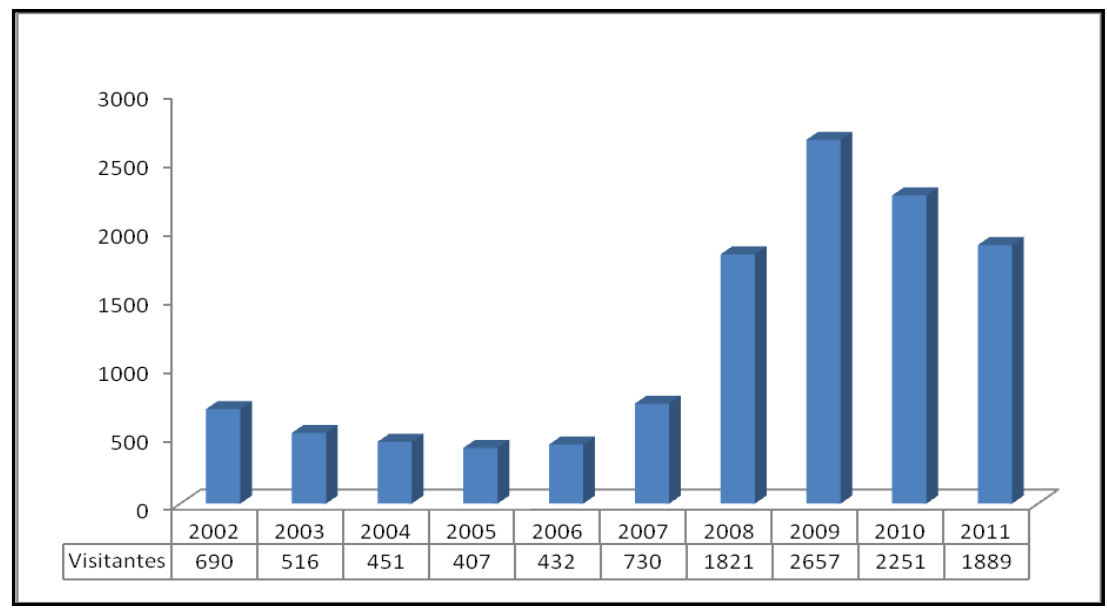

Figura 3. Fluxo de Visitantes ao OAM

Fonte: OAM (2012) elaboração própria.

Outro fato a elucidar no gráfico 1 é o ápice registrado em 2009 com 2.657 visitantes ao OAM, devido ao Ano Internacional da Astronomia 2009 (IYA2009), instituído em 2007 na Assembleia da Organização das Nações Unidas (ONU), com a adesão de 140 países, inclusive o Brasil e o OAM, cujas atividades dedicadas ao evento foram amplamente divulgadas em sítios ligados à Astronomia, inclusive da Organização das Nações Unidas para a Educação, Ciências e Cultura (UNESCO) $)^{5}$.

\section{METODOLOGIA}

Com o objetivo de analisar as atividades de lazer, acessíveis à comunidade local e turistas, utilizou-se como metodologia a pesquisa bibliográfica exploratória com enfoque no lazer, turismo e hospitalidade, além da coleta documental de dados nos sítios eletrônicos. A pesquisa qualita tiva, amplamente empregada em Ciências Sociais, fundamenta-se em entrevistas pessoais entre membros selecionados da equipe do OAM; gestores locais das áreas de turismo e/ou cultura; e residentes locais e visitantes.

Com a finalidade de analisar a relevância do OAM como espaço de lazer e de turismo, foram entrevistadas 13 pessoas, sendo três profissionais do OAM que atendem ao público; três gestores da área de turismo e/ou cultura de Valinhos e Vinhedo; três residentes da região e quatro visitantes, entre eles, um turista.

A seleção privilegiou o pertencimento do entrevistado em pelo menos um desses grupos, escolhidos também por apresentarem perfis diferenciados entre si (gênero, escolaridade, atuação profissional, procedência). Considerando-se que os resultados relacionados especificamente ao OAM foram similares, não houve necessidade de ampliar o número de depoentes. O Quadro 1 apresenta o perfil dos entrevistados selecionados.

\footnotetext{
${ }^{5}$ IYA2009 - The International Year of Astronomy 2009. UNESCO. Recuperado de ww.astronomy2009.org/general/.
} 
Quadro 1. Categoria e perfil dos entrevistados

\begin{tabular}{|c|c|c|c|c|}
\hline Categorias & $\begin{array}{l}\text { Identificação } \\
\text { do } \\
\text { entrevistado }\end{array}$ & Profissão & Perfil & $\begin{array}{l}\text { Data e } \\
\text { entrevista }\end{array}$ \\
\hline \multirow{3}{*}{$\begin{array}{l}\text { Equipe } \\
\text { OAM }\end{array}$} & Entr. 13 & Astrônomo & $\begin{array}{l}\text { Prof. livre docente do IAG/USP, } \\
\text { pesquisador e diretor do OAM. }\end{array}$ & $\begin{array}{l}\text { 05/06/2012 às } 10 \mathrm{~h} 28, \\
\text { em Valinhos }\end{array}$ \\
\hline & Entr. 05 & $\begin{array}{l}\text { Estudante } \\
\text { do IAG/USP }\end{array}$ & 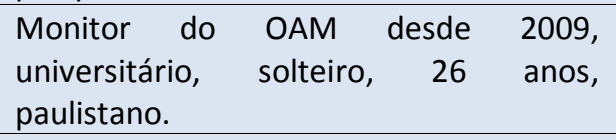 & $\begin{array}{l}27 / 04 / 2012 \text { às } 17 \mathrm{~h} 21, \\
\text { em Valinhos }\end{array}$ \\
\hline & Entr. 08 & $\begin{array}{l}\text { Planetarista } \\
\text { e } \\
\text { Técnico de } \\
\text { laboratório }\end{array}$ & $\begin{array}{l}\text { Colaborador do OAM, atende o público } \\
\text { desde 2001, universitário, casado, } \\
\text { autóctone. }\end{array}$ & $\begin{array}{l}\text { 07/05/2012 às } 11 \mathrm{~h} 17, \\
\text { em Valinhos }\end{array}$ \\
\hline \multirow{3}{*}{$\begin{array}{lr}\text { Gestores } & \text { de } \\
\text { turismo } & \text { e } \\
\text { cultura } & \text { de } \\
\text { Valinhos } & \text { e } \\
\text { Vinhedo } & \end{array}$} & Entr. 01 & Turismóloga & $\begin{array}{l}\text { Sócia-proprietária agência receptiva em } \\
\text { Vinhedo, guia de turismo, vice- } \\
\text { presidente da Associação Vinhedense } \\
\text { dos Empresários de Turismo, } \\
\text { universitária, casada, autóctone. }\end{array}$ & $\begin{array}{l}\text { 19/04/2012 às } 17 \mathrm{~h} 28, \\
\text { em Vinhedo }\end{array}$ \\
\hline & Entr. 10 & Publicitário & $\begin{array}{l}\text { Presidente da Associação dos } \\
\text { Vitivinicultores de Vinhedo, professor } \\
\text { universitário, produtor rural, solteiro, } 36 \\
\text { anos, autóctone, nunca visitou o OAM e } \\
\text { desconhecia que era aberto a visitações. }\end{array}$ & $\begin{array}{l}\text { 11/05/2012 às } 15 \mathrm{~h} 37, \\
\text { em Vinhedo }\end{array}$ \\
\hline & Entr. 11 & $\begin{array}{l}\text { Secretário } \\
\text { de Cultura e } \\
\text { Turismo de } \\
\text { Valinhos }\end{array}$ & $\begin{array}{l}\text { Superior incompleto, atua na área } \\
\text { cultural desde } 1975 .\end{array}$ & $\begin{array}{l}\text { 17/05/2012 às } 10 \mathrm{~h} 48, \\
\text { em Valinhos }\end{array}$ \\
\hline \multirow{4}{*}{ Visitantes } & Entr. 03 & $\begin{array}{l}\text { Dona de } \\
\text { casa }\end{array}$ & $\begin{array}{l}\text { Paulistana, mãe de três filhos, } 2 \text { o grau } \\
\text { completo, reside na região há } 4 \text { anos, } \\
\text { reside em Valinhos. }\end{array}$ & $\begin{array}{l}\text { 23/04/2012 às } 15 \mathrm{~h} 30, \\
\text { em Valinhos }\end{array}$ \\
\hline & & Médica & $\begin{array}{l}\text { Neurocirurgiã, pesquisadora, casada, } \\
\text { carioca, residente em São Paulo. }\end{array}$ & $\begin{array}{l}29 / 04 / 2012 \text { às } 12 \mathrm{~h} 00, \\
\text { em Vinhedo }\end{array}$ \\
\hline & Entr. 09 & Professor & $\begin{array}{l}\text { Pedagogo, de Belém do Pará, casado. } \\
\text { Visitou o OAM duas vezes. }\end{array}$ & $\begin{array}{l}07 / 05 / 2012 \text { às } 21 \mathrm{~h} 55, \\
\text { em Valinhos }\end{array}$ \\
\hline & Entr. 12 & Bióloga & $\begin{array}{l}\text { Trabalha em São Paulo com edição de } \\
\text { livros, } 53 \text { anos, casada, universitária, } \\
\text { reside em Vinhedo. }\end{array}$ & $\begin{array}{l}\text { 19/05/2011 às } 15 \mathrm{~h} 21, \\
\text { em Vinhedo }\end{array}$ \\
\hline \multirow{3}{*}{ Residentes } & Entr. 02 & $\begin{array}{l}\text { Bacharel em } \\
\text { letras }\end{array}$ & $\begin{array}{l}\text { Poeta, escritor, autóctone, ex-secretário } \\
\text { da Fazenda ex-secretário de } \\
\text { Administração Legislativa, } 64 \text { anos, } \\
\text { autóctone. Visitou o OAM diversas vezes, } \\
\text { inclusive outros observatórios no } \\
\text { exterior. }\end{array}$ & $\begin{array}{l}\text { 20/04/2012 às } 15 \mathrm{~h} 30, \\
\text { em Vinhedo }\end{array}$ \\
\hline & Entr. 07 & $\begin{array}{l}\text { Dona de } \\
\text { casa }\end{array}$ & $\begin{array}{l}\text { Ensino fundamental, casada, } 42 \text { anos, } \\
\text { residente em Vinhedo há } 20 \text { anos. Nunca } \\
\text { visitou o OAM e desconhecia que era } \\
\text { aberto a visitações públicas. }\end{array}$ & $\begin{array}{l}03 / 05 / 2012 \text { às } 10 \mathrm{~h} 15, \\
\text { em Vinhedo }\end{array}$ \\
\hline & Entr. 04 & $\begin{array}{l}\text { Massotera- } \\
\text { peuta }\end{array}$ & $\begin{array}{l}\text { Proprietária de pousada, neta do ex- } \\
\text { proprietário da área onde o OAM está } \\
\text { localizado, casada, autóctone. }\end{array}$ & $\begin{array}{l}24 / 04 / 2012 \text { às } 10 \mathrm{~h} 02, \\
\text { Divisa de Valinhos e } \\
\text { Vinhedo }\end{array}$ \\
\hline
\end{tabular}

Fonte: Elaboração própria (2012) 
Por meio dos depoimentos levantou-se a opinião sobre a divulgação científica promovida pelo OAM junto ao público, entendida como uma atividade de lazer, também destinada a turistas, bem como a sua visibilidade em diversos segmentos da sociedade, que direta e/ou indiretamente interagem com o equipamento, ou mesmo, aqueles que residem na região, e não o visitaram ainda, ou que desconhecem a sua existência e a possibilidade de visitação.

\section{RESULTADOS E DISCUSSÕES}

\section{Relevância ambiental do OAM e do céu noturno preservado}

Ao serem indagados qual a importância do OAM à preservação do meio ambiente e do céu noturno para a região, os entrevistados consideram a sua presença relevante nesses aspectos, principalmente devido à escalada da urbanização regional e temem até a transformação da sua área em condomínio, conforme abaixo:

[...] Nós precisamos de parque [...]. Talvez o terreno em torno do Observatório sirva para esta função. Porque lá se exerce uma atividade que não prejudica o meio ambiente. [...]. E, fora isso, é um lugar que tá lá preservadinho, quietinho. [...] Porque existe uma área grande lá e preservada. Então eu falo para o pessoal: "Gente, vocês começam a ir visitar o observatório, porque senão daqui a pouco não vai vir mais dinheiro pra manter o observatório e vai virar condomínio! Vai ser muito triste". (Entr. 03, grifo nosso).

[...] Mas, de certa forma, se a mata não fosse preservada, se a região do entorno fosse vendida, ou simplesmente, assim, sei lá, doada, de certa forma, remanejada para uma infraestrutura urbana, essa parte [...] o pouco que a gente tem de escuridão do céu estaria perdido. (Entr. 05)

Apesar de eu achar que isso já deveria ter acontecido já há muito tempo, de se evitar a construção de condomínios próximos ali, não é. Mas eu acho que ainda é tempo, sim. Eu acho que tem que preservar, porque ali é uma mata muito interessante. Eu acho que se perdermos ali vai ser lamentável. Vai ser uma coisa que não fará bem a ninguém, não é. (Entr. 11)

Acho que sim. O fragmento de mata que tem aqui é muito grande, é muito importante. Deve ser um dos maiores da região e, como eu disse, ele está preservado pela existência do observatório. Porque se o observatório não estivesse aqui, esse terreno já teria sido transformado [...] sei lá, em condomínio, centro comercial. Bom, mas a existência do observatório garante essa cobertura vegetal do morro, que é muito importante. Pelo menos garante, até que um dia ela se transforme numa reserva. (Entr. 13)

De acordo com Gutmann (2011), a Região Metropolitana de Campinas (RMC) passa por um forte processo de urbanização, com pontos de conurbação entre os municípios, com a proliferação de condomínios horizontais, simultaneamente ao processo de êxodo rural. Esse processo deve-se 
à demanda de famílias urbanas que buscam na região tranquilidade e segurança, com maior acesso às áreas verdes e ao lazer, isto é, uma melhor qualidade de vida, longe das mazelas dos grandes centros urbanos.

Entretanto, nota-se no depoimento da maioria dos entrevistados, a preocupação com a proliferação desses residenciais, que ocupam áreas antes dedicadas à agricultura, chegando ao entorno do OAM, e temem que a área ocupada pelo equipamento, também se transforme em condomínio.

Embora a área de aproximadamente $450.000 \mathrm{~m}^{2}$ ocupada pelo OAM seja cadastrada junto ao IBAMA para a soltura de animais silvestres, e não seja ainda legalmente preservada, o local o local deve "Promover prioritariamente a preservação e/ou adequação e/ou recuperação de uso para maior aproveitamento cultural, e turístico (Valinhos, 2004, grifo da fonte)", condições estas que o equipamento vem desempenhando adequadamente.

Todos os entrevistados, sem exceção, reconheceram a importância do OAM na questão ambiental, que funciona como uma "ilha verde" regional preservada, relevante à flora e fauna, conforme exemplos abaixo:

Só pela área que ele dispõe, e pela soltura dos animais quando o Ibama faz essa coleta, e pela quantidade de animais que ali tem, ele já tem um ponto favorável, não é? (Entr. 01)

Totalmente. Eu acho que tem que ser conservado, mas inclusive com a responsabilidade da manutenção da observação, da vigilância, da fiscalização [...]. Aí no caso é o papel público. Eu não posso ir lá e por uma cerca e eu não posso ficar de vigilante lá, não é. Isso tem que ser cuidado [...]. (Entr. 02)

(Sobre a presença do Observatório) Ajuda, porque preserva-se aquele entorno todo, não é. Ainda tá próximo da cidade? Está, mas está num miolo que tá preservado. (Entr. 03)

É fundamental. Bom,... a vegetação não tá aí por acaso, [...] preservar a mata, garante o ecossistema local. [...]. A gente tem diversas espécies de mamíferos, pássaros, [...] borboletas [...] todos os tipos. A fauna e a flora são extremamente ricas graças a essa preservação do Observatório. Então, isso tem que ser mantido porque é uma área de soltura de animais pelo IBAMA, por entidades, assim, próximas que apreendem animais silvestres que tenham sinais de maus tratos e tudo mais, alguns são soltos aqui dentro. Então é uma área importante de preservação por isso. (Entr. 05)

Neste aspecto, vale salientar o depoimento da neta do ex-proprietário da área doada ao OAM, que notou e acompanhou a expansão e recuperação da mata ao longo dos anos:

É uma área maravilhosa, que eu tenho essa área aí na minha memória, na minha vida. E eu tenho ainda a informar, uma coisa melhor ainda, que ao meu ver, com todo esse olhar todos os dias para essa mata, que graças a Deus e à natureza, ela se expandiu, não é? [...] que seja uma área de preservação oficializada, para a 
gente poder ter certeza de isso não seja destruída um dia, não é? [...] porque [...] ainda bem que elas respeitam, [...], visivelmente a mudança foi significativa, da época de quando eu era criança pra cá, ela se revitalizou. (Entr. 04)

A contemplação de um céu noturno estrelado era prática comum em outros tempos, transmitida entre gerações, lembrada por alguns entrevistados. Como, por exemplo, a nomeação das constelações estelares, cujo mapeamento surgiu na Mesopotâmia há cerca de 4.000 anos a.C, fez parte da mitologia grega, passa pelas civilizações indígenas, chegando às civilizações modernas, que as adaptavam e as interpretavam segundo a sua realidade ambiental e cultural.

Assim, além do interesse pela astronomia, questionou-se sobre a relevância atribuída ao céu estrelado. Todos os respondentes consideram fascinante um céu noturno límpido e estrelado, que atrai a sua atenção pela beleza, que faz parte do imaginário humano e de poetas:

[...] eu diria pra você que eu sou uma pessoa multifacetada, eu me interesso por tudo. Essa pergunta, objetivamente, eu vou responder assim: eu sou um poeta e eu costumo olhar pra cima e observar os astros. Eu estou sempre vendo as estrelas, observando os planetas e a lua, principalmente, que já me inspirou muitos poemas. (Entr. 02)

Eu acho maravilhoso, é assim uma coisa encantadora, porque a partir do momento que você começa a olhar aquilo, começa a ficar ainda mais interessante, não é? Hoje eu estou na correria [...], aí você acaba, de fato, não parando para pensar, mas, é uma coisa fascinante, não é? (Entr. 01)

Porque é bonito! Porque é uma coisa que está lá muito distante. E a gente fica pensando, não é, do que é feito, se tem gente morando, se um dia vai ter gente morando lá, sabe? São curiosidades mesmo [...] que a gente tem, das coisas além da Terra. (Entr. 03)

Existem as pesquisas que são fundamentais na nossa vida e que o pesquisador precisa disso, não é. Agora, pra gente, tem a parte romântica, a parte de beleza, independentemente da necessidade científica do céu estrelado pra muita gente. (Entr. 06)

Sim, porque isso é uma coisa bonita. É bonito, não é. A lua é uma coisa bonita, principalmente quando a lua está indo pra uma fase cheia e quando ela tá cheia, que fica aquela bolona de fogo no céu. Aquilo é maravilhoso, aquilo é encantador! E o céu também, quando tá bem estrelado, todo mundo, acho que quase todo mundo quando olha fala: 'Nossa, olha que maravilha!' Porque é bonito. (Entr. 12)

O conhecimento astronômico ele é, digamos, [...], a ciência mais antiga e é uma das formas principais ou foi uma das principais, eu diria a única, de se transmitir lições de cidadania pra crianças ou o próprio conhecimento da sociedade, não é. Várias civilizações plantavam quando viam o surgimento de uma estrela no céu logo depois que o sol se põe. E, hoje em dia, claro, a gente tem estações do ano, digamos, um calendário com as estações do ano tudo definido, tudo bonito, não é, mas na época isso não existia. Então, a astronomia, ela servia 
fundamentalmente pra tudo, não é. A premonição dos fenômenos terrestres, assim, pra saber quando você semeia, quando você colhe, tudo isso era muito importante. (Entr 05)

Os depoimentos acima comprovam o interesse e o fascínio pelo céu noturno estrelado, que faz parte da cultura das civilizações humanas. Entretanto, a contemplação das luzes estelares vem sendo prejudicadas pela poluição do céu, sobretudo pela poluição luminosa nos centros urbanos, provocada pelo excesso de iluminação pública, chegando inclusive a atingir o Observatório Abrahão de Moraes. Este fato, perceptível por todos, é pouco discutido na sociedade, tanto localmente, como no mundo, conforme:

Nas últimas quatro décadas, o mundo tornou-se cada vez mais sintonizado com os problemas do meio ambiente. No entanto, a poluição lúmica, e mais especificamente do céu noturno, não está em alta nas agendas dos problemas ambientais prioritários - global, regional, nacional ou localmente. (Starlight, 2007, s.p., tradução livre).

\section{Visitas públicas ao OAM: espaço de lazer e turismo}

No próximo questionamento, os entrevistados ao serem indagados o que seria lazer para eles, a maioria dos entrevistados afirmou - implícita ou explicitamente - que é uma atividade longe das obrigações e houve quem o relacionasse à uma atividade prazerosa, à introspecção, uma fuga da rotina, à qualidade de vida, e ainda à observação astronômica (caso de um colaborador do OAM):

Olha, o lazer é aquilo que a pessoa faz no momento em que ela não está trabalhando. Mas, eu entendo, que mesmo ela trabalhando é um momento que ela consegue estar incluindo o lazer, principalmente com tanta mídia disponível, enfim, o lazer é aquele momento que você se desliga, não é, do trabalho [...]. (Entr. 01)

É o ter um tempo pra você. Pra mim, pessoalmente, é essa introspecção. Fora, além do físico, tem a parte toda emocional. Então, lazer pra mim é isso. (Entr. 04) Eu nem sei o que está no dicionário. Mas, pra mim, o lazer é assim quando você está cansado, não é, você quer distrair um pouco, espairecer, aí você faz aquilo que você gosta. Então, minha opinião é meio suspeita, não é, porque pra mim, a astronomia, essa astronomia, o hobby, prazer de olhar o céu por divertimento, pra mim, isso sempre foi um lazer [...]. Mas, pra mim, astronomia assim, pegar um binóculo sem compromisso e olhar o céu por hobby, pra mim é um super lazer. (Entr. 08)

Lazer [...] é fazer algo que não esteja sistematicamente ligado ao trabalho, que dê prazer, não é, precisa dar prazer, precisa não estar ligado ao trabalho, aquela rotina do trabalho, atividades. São atividades prazerosas que se formam, que [...] desenvolvemos fora [...] das atividades do trabalho comum, assim. (Entr. 09) 
Eu vejo lazer como qualidade de vida, [...]. Às vezes, você tem muitas propostas de lazer que você sai muito mais cansado da onde você tá, do que aquilo te dá [...] você acaba não gostando, mas não te interessa pra voltar de novo, não é. (Entr. 10)

Ah, eu acho que lazer é tudo aquilo que te acrescenta alguma coisa sem a obrigação de, por exemplo, sem aquele compromisso que você ter que fazer porque é obrigado, não é. Lazer eu acho que é, que tem que unir a descontração, [...] tem que ser uma coisa agradável. (Entr. 11)

Assim, os depoimentos apresentados acima ajudam a corroborar a concepção de Dumazedier (2000, p.34):

O lazer é um conjunto de ocupações às quais o indivíduo pode entregar-se, de livre vontade, seja para repousar, seja para divertir-se, recrear-se e entreter-se ou, ainda, para desenvolver sua informação ou formação desinteressada, sua participação social voluntária ou sua livre capacidade criadora, após livrar-se ou desembaraçar-se das obrigações profissionais, familiares e sociais.

Embora o senso comum possa acreditar que o lazer seja apenas diversão e descanso, deduz-se que a prática das atividades de lazer fornece ao indivíduo oportunidades de desenvolvimento pessoal, bem estar social, além de um equilíbrio das necessidades de ordem individual, cultural e comunitária.

Todos os entrevistados acreditam que a visita ao OAM ou a outro observatório astronômico seja uma forma de lazer, e para alguns uma experiência peculiar, e até emocionante, conforme a seguir:

É um lazer. Pra quem gosta, é um bom anti stress. É pra espairecer da correria do dia a dia. Então, pra mim, é lazer. (Entr. 08)

Eu acredito que pra mim foi uma coisa surpreendente, porque eu não imaginava, eu nunca tinha visto o céu através de um telescópio. Eu já tinha ido em planetário, mas não é a mesma coisa. E observar no telescópio, que você bota o olhinho lá e você vê a lua, não é, e as crateras da lua, é impressionante isso pra mim. Impressionante. Foi muito emocionante. (Entr. 12)

Eu imagino que seja mais nesse sentido, não é. Por isso que eu [...] e você, às vezes, observando o céu como forma de lazer, você está absorto [...] você dá cordas pra aquilo que tem dentro da cabeça das pessoas e acaba imaginando, instiga [...]. Eu acho que propicia também [...] essa questão da curiosidade, não é. Então, eu imagino que isso tenha a ver com lazer também. Sim, porque você esquece do dia-a-dia. [...] Você tem uma fuga, você tem o pensamento voltado pra outras coisas que não aquelas coisas do compromisso diário com isso, com aquilo, não é. (Entr. 11)

Sem dúvida, é uma forma de lazer. E eu diria uma forma de lazer extremamente rica e rara. É muito diferente. [...] mas visitar um observatório é mais raro porque 
a disponibilidade desses locais é muito menor do que de algumas atividades mais comuns, não é, e no observatório ainda onde se faz pesquisa científica é mais raro ainda. Então, existem observatórios amadores, que são muito interessantes, mas são em número também bastante reduzidos. Mas a visita a um observatório onde se faz pesquisa científica, ele também é interessante, é rico e é mais raro, não é.

(Entr. 13)

Além disso, a partir dos depoimentos apresentados a seguir, constatou-se que o lazer proporcionado no OAM seja uma forma de transmitir conhecimento (astronômico), isto é, promove a educação não-formal:

Eu procuro extrair essas duas funções de cada lugar que eu vou: tanto o conhecimento, quanto o lazer [...]. Então, é assim, é um momento de lazer e ao mesmo tempo de conhecimento. Então, lidar com essa possibilidade de você ter uma estrutura que te permita ter uma coisa prazerosa e, ao mesmo tempo, trazer conhecimento é fantástica. Porque nós, quanto mais ludicamente nós aprendemos, melhor [...]. Concordo plenamente, é um lazer socioeducativo. Ao mesmo tempo em que as pessoas se divertem, elas aprendem. Principalmente em família, envolvendo os filhos. É importante para os cidadãos leigos porque, para se gostar de alguma coisa, é preciso conhecer. A partir do conhecimento é que cresce o interesse [...]. Eu acho fantástico disponibilizar a oportunidade. O lazer cultural. Por quê? As pessoas são tão cegas e tão distantes desse conhecimento, que só aproximando-as desse conhecimento, elas vão passar a gostar. (Entr. 02)

(É uma forma) De lazer e de aprendizado [...].'Olha, vem aqui ver. Tá vendo o que eu tô vendo? Achei legal.' É diferente [...], que eles vão, apontam e aí todo mundo vai, tira suas dúvidas, olha de novo e se despede daquela imagem e fica esperando voltar quando o céu tá diferente.

(Entr. 03)

E ainda:

[...] o observatório é o local onde os visitantes tem contato direto com o pesquisador. Eles têm a oportunidade de esclarecer suas dúvidas com cientistas diretamente. (Entr. 05)

[...] esses programas turísticos são muito mais mesmo pra dar prazer, pra você satisfazer as curiosidades, não é. Responder várias perguntas que estão no ar. Então, eu acho que é muito prazeroso, fora que, olhar céu sempre é prazeroso pra qualquer pessoa, de um modo ou de outro. Romântico ou pra satisfazer curiosidade. (Entr. 06, grifo nosso)

É uma forma de inclusão social. Dá muito mais conhecimento. Então, aí, quer dizer, hoje o Estado e a prefeitura, elas têm verba pra gastar com isso. [...] porque não fazer também programas voltados pra essa parte, não é? Parte cultural. [...] Que tanto prefeitura, como Estado se organizem, possam se organizar pra [...] promover, disponibilizar esse serviço pra comunidade, pra população em geral, não é. Não só aqueles que têm mais condições, não é, mas aqueles que têm menos condições. Você educa a pessoa e faz com que a pessoa conheça mais coisas e não viva só no mundo da internet. (Entr. 10, grifo nosso) 
Observatórios e um céu noturno preservado podem ser atrativos turísticos, conforme os depoimentos a seguir:

O Observatório [OAM] é importante para preservação, pois é através dele que o público toma maior conhecimento do trabalho do astrônomo/geofísico/meteorologista. Assim, todos entendem o quão importante é a preservação do meio ambiente tanto para a pesquisa, como também para a sociedade. A preservação de um céu limpo, tanto no que diz respeito à poluição atmosférica como também em relação à poluição luminosa, é a principal informação ambiental salientada no Observatório e podem ajudar principalmente a enriquecer a qualidade de vida encontrada nas cidades próximas e também no aumento do número de turistas. (Entr. 05)

E de vez em quando a gente já viajou pra fazer isso [...]. É muito importante. Tem cidades que são conhecidas pelo céu limpo, [...]. São conhecidas pelo céu limpo, pela noite bonita [...]. Especificamente atrás do céu só no Havaí mesmo, quando a gente foi pro observatório nesse interesse específico de observar estrelas. A gente também foi pra Pedreira, especificamente pra gente olhar estrelas. (Entr. 06, grifo nosso).

Vários depoentes consideram esta atividade como uma oportunidade do exercício da cidadania, além do contato do público com pesquisadores e acadêmicos, fato incomum no cenário brasileiro:

Muito raro, é muito raro. Vamos dizer, [...] fora os museus, nenhuma universidade se abre pra receber a população, assim, por exemplo, a que faz, não é. Você não vê um laboratório dentro de uma universidade [...] digamos assim, porque seria interessante, como se fosse num museu com um guia, vendo. "Olha, aqui fica o laboratório do fulano, que trabalha com isso", não é. (Entr. 09)

Mas a visita a um observatório onde se faz pesquisa científica, ele também é interessante, é rico e é mais raro, não é [...]. Então eu acho que é uma atividade de lazer, mas uma atividade de lazer muito rica, muito rica, porque você pode ter contato com o que se faz ali de científico, numa área muito antiga da pesquisa científica, que é a astronomia, não é. Nesse caso aqui do Abrahão de Moraes, você entra em contato com astrobiologia, que é uma área muito nova, e tal. Você pode satisfazer algumas curiosidades. (Entr. 13)

Vale ressaltar que o OAM proporciona um lazer educativo interativo, além de um atendimento personalizado, longe do turismo de massa, que de acordo com Krippendorf (2000) deve ser almejado pelos turistas e viajantes responsáveis, e ainda segundo Molina (2002, p.138 tradução livre): “Obviamente, estes turistas estão atrás de experiências responsáveis e significativas, capazes de enriquecer a sua existência.", o que ocorre no OAM, segundo a depoente:

Muito raro, até porque a gente se sente um pouco participante. Por ser um grupo pequeno pra observar, por ter essa característica de não ser ainda um espaço 
dedicado ao turismo e à observação, você se sente um pouco sendo atendida como um visitante especial num centro de pesquisa. Então você não tá indo, pagando, comprando um ticket pra ver... Você vai lá pra uma sala, onde eles explicam várias coisas. [...]. Então, porque não tem esse caráter ainda, vamos dizer, de massa, massificante de um ponto de turismo. É mais como se eles permitissem que a gente pudesse visualizar o trabalho deles uma vez por mês. (Entr. 12)

A partir dos depoimentos dos entrevistados nota-se nitidamente a transmissão de conhecimentos astronômicos por meio da educação não-formal promovida pelo OAM, além da possibilidade de entender o "que faz" e "o que é" um observatório astronômico, ou seja, a busca em aprender e entender o objeto da visitação; conforme definição do (MTUR, 2010, p. 16) para o turismo cultural:

O Turismo Cultural implica em experiências positivas do visitante com o patrimônio [...] e determinados eventos culturais, de modo a favorecer a percepção de seus sentidos e contribuir para a sua preservação. Vivenciar significa sentir, captar a essência, e isso se concretiza em duas formas de relação do turista com a cultura ou algum aspecto cultural: a primeira refere-se às formas de interação para conhecer, interpretar, compreender e valorizar aquilo que é o objeto da visita [...]

De acordo com Dumazedier (2000) o lazer desempenha três funções: descanso (em resposta à fadiga); divertimento, recreação e entretenimento e de desenvolvimento, com novas formas de aprendizagem, sendo uma delas, a aquisição de noções de astronomia.

\section{OAM: Hospitalidade e visibilidade turística}

Ao serem questionados se foram bem recebidos e se a equipe é hospitaleira foi unânime a excelente avaliação sobre o atendimento ao público do OAM entre os visitantes, que superam as ressalvas à infraestrutura, comentada por alguns. Embora seja um espaço utilizado ao atendimento público, os visitantes se "sentiram em casa", e à vontade, ou seja, sentiram-se acolhidos, característica da hospitalidade, conforme segue:

Nossa, excelente! Como eu falei, parecia que a gente tava sendo recebido pra uma visita especial ali, podendo observar o trabalho deles, o mundinho deles, as salas deles. Foi excelente. Não tenho o que falar. A gente se sentiu em casa, assim. São super hospitaleiros! (Entr. 12)

Muito, muito, todas as vezes. Dependendo por quem fomos atendidos, a gente teve que ficar de olho no relógio, é muito encantador! O tempo vai passando, e não tem como controlar por períodos, e dependendo da pessoa que vai dar a recepção ela é ainda mais calorosa no papo e na ilustração sobre a observação fica melhor ainda. (Entr. 01)

Muito. Os meninos, não é, esses estudantes, [...] são [... ], assim, amorosos, não é. Eu gostei muito! (Entr. 04) 
[...] São excelentes. Eles são excelentes! Pena que realmente a gente não guarda o nome de todo mundo. Mas na ocasião da minha visita tinha muito monitor lá, e eles são excelentes. [...] Que eles largam tudo lá em São Paulo e vem passar fim de semana num [...] alojamento, no meio do nada. Mas eles vêm, você vê que eles vêm contentes. [...] A gente percebe que eles estão no ambiente que eles querem. E eles não vêm [...] com pressa, não vêm mal humorados. (Entr. 03)

Eu acho que teve muita boa vontade. Eu acho que teve um esforço até maior do que a capacidade do observatório. Ele peca um pouquinho em infraestrutura e as pessoas lá tentam suprir isso. [...] O pessoal daqui tenta suprir ao máximo as deficiências que tem de infraestrutura mesmo. (Entr. 06)

E também:

Mesmo quando a gente fazendo a visita durante o dia. Eu fiquei supresa! Eu ficava imaginando, nossa! O que nós vamos fazer lá durante o dia?! Mas não, eles montam uma apresentação, eles conseguem mostrar, e as pessoas ficam fascinadas da mesma forma, um ambiente, se eles tivessem um ambiente onde eles tivessem um auxílio, uma ajuda mais fortalecida, num ambiente, onde as pessoas tinham que sentar no chão, dentro do espaço, onde você não tem banco, não tem cadeira, então você tem que sentar no chão mesmo [...]. (Entr. 01)

Entendendo-se que a hospitalidade é constituída da reciprocidade entre visitados e visitantes, percebe-se claramente a preocupação da equipe de anfitriões do OAM em agradar ao público, em adaptar a linguagem ao perfil do visitante, e mesmo em superar a frustração dos visitantes quando no evento "Noite com as Estrelas", não houver possibilidade de observações astronômicas in loco, em virtude das condições meteorológicas:

Então, o que eu acho legal das visitas quando as pessoas vêm, que eu atendo, eu sempre procuro conversar e ver o que (é) que a pessoa gostaria que fosse falado. Então, você não faz sempre igual, você muda. Isso é bom pra quem vem e é bom pra quem faz. Então, amanhã mesmo vai ter uma visita aqui. Vai vir uma escola infantil. Atender criança é gostoso, só que você tem que falar diferente, senão eles não entendem nada. E parece que é uma pré-escola. Eles nem são alfabetizados. E até a professora falou que eles estão lendo, quer dizer, as professoras leem pros alunos o livro 'O pequeno príncipe', porque é um livro bem infantil e fala de astronomia. [...] então estou acabando de ler de novo ' $O$ pequeno príncipe'. [...] Então você adapta a sua linguagem de acordo com o público. [...] Isso é muito importante. [...]. (Entr. 08)

É muito comum a pessoa ir num lugar em que vai tentar fazer observação com telescópio, vai tentar ver um fenômeno que ela tá esperando e em cima da hora ela recebe a notícia que não deu certo, não é. Isso frequentemente acontece no observatório, porque a gente não pode impedir que chova, a gente não pode impedir que o céu fique nublado. Então, nosso trabalho, e a gente têm sido muito 
felizes nisso, é tornar que a visita da pessoa não seja perdida e que ela veja que ela aproveitou muito e que é uma chance, digamos, de conhecimentos novos, que ela não teria se ela tivesse visto no telescópio. (Entr. 05)

E ainda, de acordo com os entrevistados abaixo, o mais importante para um bom atendimento no OAM é o trabalho em equipe, e a maneira do trato com o público, mais personalizada e espontânea:

A gente improvisa muito. [...] Mas tem muito coração nisso. E acho que isso é muito legal, é muito bom. (Entr. 13)

[...] Muitas vezes, no dia a dia a gente corre, mas na visita, eu não gosto de fazer corrido. Porque também eu acho que se for fazer correndo, eu não consigo fazer bem feito. Então, uma coisa que eu acho que deve ser feita é assim: faz com calma, não tem pressa. Além do que quem veio aqui, muita gente vem aqui como passeio, ou turismo. Então, a pessoa também não tem pressa de ir embora.

[...] Mas eu acredito que uma coisa que é muito legal pro observatório que é a alma do observatório, que chama muito a atenção, além de ter uma equipe treinada pra atender [...] porque não adianta ter telescópio bom, mas não ter quem saiba atender. Então, é ter uma equipe boa pra atender e ter bons telescópios. (Entr. 08, grifo nosso)

Esta preocupação por parte dos monitores do OAM é comprovada pelo depoimento da visitante:

É, eles são estudiosos, têm acesso a informações diferentes das nossas, mas eles conseguem nos passar isso muito bem. Não existe aquela coisa assim: 'Oh, ele falou e eu não entendi nada, mas eu vou dizer que tá tudo bem, porque senão ele vai achar que eu sou uma pessoa desinformada.' Não! Eles estão ali, assim, dispostos a nos mostrar aquilo tudo e a explicar. E, se perguntado vinte vezes, eles explicam as vinte vezes. Isso é muito legal. Esse cuidado, esse interesse em divulgar o objeto de estudo deles. [...] Eles não são lacônicos, eles são falantes, eles são animados, eles são jovens. Isso é bem legal! (Entr. 03)

As possibilidades de expressão da hospitalidade revelam ramificações significativas na compreensão da sociedade e de suas ações, refletidas na interação entre visitantes e visitados. Assim, a hospitalidade deve ser considerada sob essas duas perspectivas, ou seja, segundo Camargo (2004) e Lashley e Morrison (2004) a hospitalidade é o ato de dar-receber-retribuir, que pressupõe a mutualidade. Portanto, a hospitalidade é uma via de mão dupla, cujos personagens desenvolvem uma relação de troca, positiva ou negativa, entre o anfitrião e o visitante, e segundo Lashley e Morrison (2004, p. 21):

O entendimento mais amplo a respeito da hospitalidade sugere, em primeiro 
lugar, que esta é, fundamentalmente, o relacionamento construído entre anfitrião e hóspede. Para ser eficaz, é preciso que o hóspede sinta que o anfitrião está sendo hospitaleiro por sentimentos de generosidade, pelo desejo de agradar e por ver a ele, hóspede, enquanto indivíduo.

Neste contexto, deve-se esclarecer que "hóspede" deve ser entendido como visitante, em qualquer espaço, que não o seu habitual, segundo Camargo (2004).

Considerando-se o exposto, é o que ocorre no ambiente do OAM, pois os monitores recepcionam e entretém os visitantes, motivados em agradá-los; além disso, para evitar distanciamento e serem compreendidos, procuram adaptar a linguagem ao perfil do público. 0 depoimento da entrevistada abaixo mostra o sentimento de acolhida e de segurança, e elogia a maneira como são recepcionados no OAM:

[...] Receber grupos que eles conseguem atender, ter lugar pra estacionar. A gente se sente seguro lá. No observatório. A gente se sente seguro. É muito bem organizado e é aquela situação de você tirar suas dúvidas com pessoas que estudam isso. Não são, assim, pessoas treinadas para atender pessoas, simplesmente. São pessoas que vivem disso. São pessoas estudiosas. Isso é legal, não é? Porque [...] ah, envolve paixão mesmo, não é. Envolve paixão. (Entr. 03)

O próprio gestor tem a mesma opinião:

Eu acho que o público, em geral, fica extremamente satisfeito com o contato. Eles se sentem aqui bem recebidos, bem tratados, eu recebo de braços abertos, não é. Embora a gente não possa oferecer um coquetel, um vinho, um champagne e tal, mas eu acho que eu não me lembro de nenhuma pessoa que tenha saído daqui descontente e tal. Em geral, vêm pra cá e saem daqui muito, muito contentes. (Entr. 13)

Assim, esse atendimento personalizado procurado pelos atendentes do OAM, com respeito à diversidade de perfis dos visitantes, é o que se pode chamar de respeito à alteridade, como um valor nas relações de hospitalidade estabelecidas, onde o "outro" (o visitante) assume uma relevância maior do que a própria identidade, cultura e conhecimentos (astronômicos, neste caso específico) dos anfitriões, conforme Baptista (2005; 2008).

A maioria dos monitores são estudantes voluntários do IAG/USP, que sem nenhuma espécie de compensação material, nem financeira, e certo desconforto, em um alojamento "no meio do nada", como dito pela entrevistada 03, acompanhados também pelos colaboradores do OAM, que doam parte do seu tempo livre, em prol dos visitantes, com a finalidade única de transmitirem conhecimentos astronômicos/científicos, pouco usuais da realidade cotidiana dos visitantes, e que envolve "sacrifícios", conforme depoimento do diretor do OAM:

Por exemplo, nós temos aqui pra desenvolver atividades que a gente desenvolve, tem sacrifício de funcionários, meu mesmo e mais. Meu ainda tudo bem, mas e os funcionários, que trabalham aqui fora do horário de expediente e tudo mais, entende? Nós estamos além da nossa capacidade. [...] (Entr. 13) 
A "retribuição", um dos tripés da hospitalidade, durante essas visitas no OAM, ocorre na interação entre visitados e visitantes, quando estes, por exemplo, fazem uma simples pergunta, a qual pode promover ao monitor (pesquisador ou colaborador), um autoquestionamento e uma reflexão sobre a sua postura junto ao público, conforme depoimentos abaixo:

O pessoal acadêmico, eles estão tão ocupados, tão focados no que eles tão fazendo que às vezes soa como perda de tempo você parar e explicar pra alguém que não tem nada a ver com o assunto. Tem muita gente que acha isso, mas é impressionante quando você para pra explicar o seu trabalho pra uma pessoa que não tem nada a ver com o que você faz, como você acaba percebendo o quão você pode, digamos assim, aprender mais pra explicar aquilo pra alguém, não é. É um autoconhecimento, assim, você acaba se pegando numa situação que você vê que nem tudo que você sabe, assim, tá tão bom e que você pode realmente melhorar em vários aspectos. (Entr. 05)

[...] uma coisa que é muito importante também, é que os monitores, nessas atividades, eles aprendem muito. Aprendem muito astronomia, mas aprendem muito da interação com o público, falar, dirigir ao público, falar com as pessoas. Para a formação deles, essa atividade é muito importante. Eles crescem muito. $E$ eu acho também que a gente, de uma maneira geral, nós aprendemos sempre, não é. E na interação com o público, a gente aprende e o público também acaba aprendendo [...]. (Entr. 13)

Além disso, é interessante destacar o depoimento do diretor a respeito da maneira como a equipe do OAM efetua o atendimento ao público, ou seja, a hospitalidade exercida no OAM junto ao público é espontânea e genuína, e não dirigida, fato tão comum na hospitalidade comercial:

É espontâneo. Nunca precisei pedir aos monitores: 'Olha, faça isso, faça aquilo, receba assim.' É espontâneo, muito, muito de coração. [...] Acho que o monitor tem um comportamento que vai muito de encontro à minha maneira de ser e tal. É que nós não estamos numa empresa, com aquele sorriso global, repetindo uma frase. Realmente, é espontaneidade. Muito importante. [...] Eu diria mesmo que é fundamental essa espontaneidade, não é. [...] se a gente tivesse aqui um grupo aí de monitores que tivessem recebendo um bom dinheiro pra desenvolver essa atividade e tal, eu acho que ela não seria melhor. (Entr. 13)

[...] É não fazer mecânico. (Entr. 08)

Portanto, as atividades de divulgação cientifica do OAM destinadas ao público possuem características de hospitalidade, que foram bem avaliadas pelos visitantes. Outra unanimidade entre os entrevistados, inclusive entre o pessoal do OAM, é a reduzida visibilidade do OAM junto à população local. A maioria da população desconhece a sua existência e principalmente a possibilidade de visitação. Aqueles que têm conhecimento da existência do equipamento acreditavam que pertencia a Vinhedo e não a Valinhos, devido ao acesso por aquele município: 
[...] tinha gente que nem sabia que tinha o observatório aqui e mora em Valinhos. E sempre que eu vou em algum lugar, sai algum assunto, eu falo do observatório pra ver se fica conhecido, não é. (Entr. 08)

Tem uma divulgação, mas não tenho levado, tem que ter maior divulgação que fala dos roteiros, tem que ter mais divulgação, não é?

[...] ele poderia ter visitas mais constantes, não é? Ele poderia, na minha opinião poderia ser mais aberto ao público! Mais acessível, assim, à própria população. Não que eles não sejam, mas a pessoa que não tenha nenhum conhecimento, ela fica então mais inibida para chegar até o Observatório, agendar, fazer uma visita, não é? Ela tem que ser uma pessoa com um pouco mais de interesse. (Entr. 01)

Porque depende de despertar o interesse meu. Um dia vou até lá. (Entr. 07)

Então, quando eu falo pro pessoal: 'Pessoal, pelo amor de Deus, vá no observatório, porque senão vai virar condomínio.' É verdade. É uma coisa, infelizmente [...] séria. Porque passa-se por cima de estudo, de pesquisa, de equipamento, de preservação [...] pelo dinheiro. Não é difícil. E aí, vão dizer: 'Olha, mas tem em São Carlos, que é logo aqui. Tem o de Souzas.', mas, gente, esse é nosso! Tem que haver um meio de preservar ele. Tem que haver uma maneira. E não é tão difícil. Nós temos tantas escolas aqui. Gente, nós temos aí, duas ou três escolas em cada bairro. Gente, que as escolas que deem um jeito de ir uma vez por mês cada escola lá, nossa, tem trabalho por muito tempo. Tem que haver uma maneira. (Entr. 03)

[...] Se você sair na rua que nem a Tribuna sai e fala assim 'Você sabe que tem um observatório? Você sabe onde fica o observatório X?' Não sabe. 'Você já foi lá alguma vez?' Com certeza, a pessoa vai dizer não. (Entr. 02)

Ao serem indagados se existe divulgação suficiente do observatório na região os entrevistados responderam unanimemente que não há:

Ah, deveria ter mais informações, assim, por exemplo, quando alguém chega até o Memorial, que esclarecesse, que falasse sobre [...]. [...] que fosse sempre motivado a essas pessoas que são os munícipes e visitantes da região, que visitem, que frequentem o Observatório, porque assim, além de poderem visualizar uma coisa, e poxa, dizer, mas isto é magnífico, não é, vão fazer com que os outros também tenham conhecimento [...]. então é sempre necessário passar esta informação. (Entr. 01)

Ah, não. Não, porque as pessoas continuam saindo daqui pra ir pro planetário. Que é uma coisa que [...] demanda uma organização de um dia inteiro. E as pessoas continuam fazendo isso. O planetário tem a sua função, mas o observatório é uma experiência muito diferente. A gente sai daqui, vai até São Paulo pra ver o planetário, e não sabe que tem o observatório aqui em Valinhos.

[...] Então, porque o fato é que tem que ser mais divulgado porque as pessoas não conhecem ou se conhecem não acreditam que seja tão fácil agendar [...]. (Entr. 03) 
Não. É pouco visível. Pouco conhecido. Pouco divulgado [...]. Não existe divulgação. (Entr. 12)

Foram sugeridos alguns meios de divulgação dessas atividades públicas do Observatório:

Eu procuraria ter, assim, alguma coisa fixa nos jornais, nos órgãos de imprensa da cidade, articulistas, pessoas que pudessem ter uma página ou uma coluna e você ir estimulando através dessa coluna [...]. Simplificando: é um processo de comunicação. As pessoas precisam saber que tem e como é que funciona. (Entr. 02)

Olha, eu acredito que pra região, ele poderia ser divulgado através de folhetos mesmo, não é. [...] Poderia ter um flyer, [...] sobre o observatório. [...] Mas o que faz, como você pode observar, tal, isso eu não sei. E aí fazer uma divulgação também, acho que em São Paulo, não é, que é bem próximo daqui, [...] que o povo é todo doido pra sair de lá um pouquinho, fugir. $E$ aí eu acho que poderia fazer uma divulgação nesse sentido. Em rádios, não é. Tem várias rádios que dão programações culturais, científico-educacionais e poderiam divulgar isso. (Entr. 12)

Www! (risos). Hoje em dia, todo jovem tem internet. Então tem que ter uma palavra-chave muito boa, e que ele entrasse na página, e que a página fosse muito atraente. Seria o maior convite.

Bom, então, aí que está, tem que ver pra que público. Eu sou uma pessoa interessada. Eu já procurei observatórios em outros lugares, tenho facilidade de acesso e tudo. [...] É diferente de uma pessoa que teria que ser atraída pela página, não é. (Entr. 06)

No jornal. Pelo jornal sai bastante coisa. Pelo Jornal de Vinhedo. Eu leio. Sai toda informação, não é. (Entr. 07)

Também foi lembrado que para incrementar a sua visibilidade e possibilitar o prosseguimento das suas atividades de divulgação científica é necessário o apoio do setor público, inclusive financeiro, para melhoria da infraestrutura:

Eu acho que recurso é importante, porque eles não têm. É uma coisa que você vai lá e é gratuito ou então é um valor simbólico. Que pras pessoas conhecerem é interessante, mas não dá pra manter um lugar desses sem ter outro recurso. Tem que ter um recurso financeiro pra estar melhorando ali e isso tem que vir de algum órgão aí que possa estender a mão ali, não é. Sempre com interesse pra eles, porque tem que movimentar, não é. As pessoas, acho que tem que se interessar mais, fazer uma divulgação do observatório pra poder mobilizar as pessoas, pra você conseguir com que a prefeitura ou o Estado ajude, não é. (Entr. 04)

Então, acho que pra tornar o observatório mais conhecido, nós temos que alterar a infraestrutura material e humana aqui. Não dá. Eu gostaria que o observatório fosse mais conhecido? Eu gostaria, mas não é possível. Não é possível nós 
fazermos uma divulgação maior do nosso trabalho, que vamos atrair mais público, se nós não temos condição. (Entr. 13)

Os depoimentos dos entrevistados corroboram que os visitantes do OAM observam o céu noturno movido pela beleza, pelo fascínio que o mistério do Universo desperta, procurando entender o seu funcionamento e os fenômenos relacionados aos eventos cósmicos, ou seja, faz parte da cultura humana, passada entre as gerações, segundo a Organização das Nações Unidas para a Educação, Ciências e Cultura (UNESCO, 2012) e Starlight (2011).

Esta pesquisa permitiu apurar também, a hospitalidade ali exercida, que foi unanimemente percebida pelos visitantes, fato que pode representar também um elemento motivador à continuidade dessas atividades públicas. A hospitalidade é estabelecida entre pessoas nos domínios domésticos, públicos, comerciais, e até virtuais, baseada no tripé dar-receber-retribuir, em um processo contínuo, com algum sacrifício pessoal, e ainda com respeito à alteridade do outro protagonista (Baptista, 2005; 2008), o que ocorre no OAM, de acordo com o depoimento dos entrevistados.

Nos aspectos das entrevistas realizadas e as análises desenvolvidas, houve também unanimidade quanto à reduzida visibilidade do OAM junto à população local, e como atrativo turístico, cujas atividades de difusão científica deveriam ser divulgadas pela mídia local, e apoiadas pelas respectivas prefeituras municipais.

\section{CONSIDERAÇÕES FINAIS}

Este estudo com suas peculiaridades, demonstrou a possibilidade do desenvolvimento de uma modalidade de turismo e de lazer realizada em observatórios astronômicos, que abrem seus espaços à visitação pública, geralmente guiada, promovendo a educação não-formal.

Essas atividades devem ser entendidas como um lazer socioeducativo flexível, voluntário e democrático, ou seja, a busca de desenvolvimento pessoal com a aquisição de informações e noções sobre astronomia, além da possibilidade de observações astronômicas in loco, e em alguns casos específicos, como o OAM, a oportunidade de um contato "ao vivo e a cores" com o mundo científico - um lazer raro -, que deveria ser mais fomentado, inclusive no segmento turístico.

Cabe ressaltar que esta pesquisa de caráter exploratório e qualitativo aborda uma temática pouco estudada em Ciências Sociais: a fruição do lazer e do turismo em um observatório astronômico, portanto, pretende contribuir com reflexões a respeito desse fenômeno social. Nesse sentido, sugerem-se outros estudos que busquem compreender as manifestações de hospitalidade no contexto da visitação em observatórios astronômicos. Nota-se nas discussões apresentadas a quebra de um paradigma. Observa-se, aqui, o fato de instituições científicas também serem vetores de atratividade turística motivadas principalmente pelos aspectos apontados por este estudo.

Observou-se também, que a busca pelo conhecimento transforma a ação do visitante de forma a criar uma maior participação do mesmo nos eventos, além se servir de elemento 
motivador, por exemplo, para melhorar a ação didática daqueles que trabalham no Observatório. Nesta perspectiva, de análise percebe-se assim a manifestação da hospitalidade como sustentáculo de uma ação de aproximação entre as pessoas, no legítimo exemplo das relações estabelecidas entre os anfitriões e seus hóspedes.

\section{REFERÊNCIAS}

Baptista, I. (2005). Para uma geografia da proximidade humana. Revista Hospitalidade, São Paulo, ano 2, 11-22,

(2008). Hospitalidade e eleição intersubjectiva: sobre o espírito que guarda os lugares. Revista Hospitalidade. São Paulo, ano V, 2, 5-14.

BRASIL - MTUR - MINISTÉRIO DO TURISMO. Turismo Cultural: Orientações Básicas. Brasília: Ministério do Turismo, 2010. Recuperado de http://www.turismo.gov.br

Camargo, L. O. L. (2004). Hospitalidade. (2a ed.). Coleção ABC do Turismo. São Paulo: Aleph.

. (2003).Os domínios da Hospitalidade. In Dencker, A. de F., \& Bueno, M. S. Hospitalidade: cenários e oportunidades. São Paulo: Thomson.

Dumazedier, J. (2000). Lazer e Cultura Popular. (3a ed.). São Paulo: Perspectiva.

(1999). Sociologia empírica do lazer. São Paulo: Perspectiva.

Gutmann, S. C. (2011). O valor patrimonial dos espaços públicos: estudo de caso do centro de Valinhos-SP. Dissertação (Mestrado em Urbanismo) - Pontifícia Universidade Católica de Campinas, Centro de Ciências Exatas, Ambientais e de Tecnologias, Pós-Graduação em Urbanismo. Campinas.

Lashley, C., \& Morrison, A. (Org.). (2004). Em busca da hospitalidade. Perspectivas para um mundo globalizado. São Paulo: Manole.

Langhi, R., \& Nardi, R. (2009). Ensino de Astronomia: educação formal, informal, não formal e divulgação científica. Revista Brasileira de Ensino de Física, 31(4), 4402.

Linhares, F. R. C. (2011). O objetivo das visitas escolares a um observatório astronômico na visão dos professores. 239p. Dissertação (Mestrado em Educação). Faculdade de Educação, Universidade Federal de Minas Gerais, Belo Horizonte, Minas Gerais.

Molina, S. (1998). Turismo y Ecologia. (6a ed.). México: Trilhas. (reimp. 2002).

Montandon, A.(dir.) (2011).O livro da Hospitalidade: acolhida do estrangeiro na história e nas culturas. São Paulo: SENAC.

Mourão, R.R.F. (1994). Dicionário de Astronomia e Astronáutica. Rio de Janeiro: Nova Fronteira.

NASA - Picture of the day. Recuperado de http://apod.nasa.gov/apod/astropix.html

Observatório Abrahão de Moraes. Valinhos ou Vinhedo? Conheça o Observatório Abrahão de Moraes. Recuperado de http://www.usp.br/mapas/materia01.html. . (2012). Gráfico 1. Fluxo de visitantes. Correio eletrônico.

Starlight. The International Conference in Defense of the Quality of Night Sky and the right to observe stars. Disponível em: <http://www.starlight2007.net>. Acesso em: 26 nov. 2011.

Teixeira, R. Observatório Abrahão de Moraes. Entrevistas, contatos telefônicos e eletrônicos em 2009, 2010, 2011 e 2012. 
Tomanik, G. B., \& Bastos, S. R. (2012). Um patrimônio da humanidade ameaçado: o céu noturno. In Anais do IX Seminário da ANPTUR - Turismo e Patrimônio. São Paulo: Aleph, 1., pp. 1-13.

Tomanik, G. B. (2011). O Aspecto do Lazer e do Turismo Cultural: Visitas ao Observatório Abrahão De Moraes (IAG-USP). In Anais do VIII Seminário ANPTUR - Seminário Anual Associação Brasileira de Pesquisa e Pós-Graduação em Turismo, Balneário Camboriú-SC. São Paulo: Aleph.

Tomanik, G. B. (2011). Observatório Abrahão de Moraes (IAG-USP): uma opção de lazer e de turismo sustentável em um cenário natural. In: Anais do VIII CONECOTUR - Congresso Nacional de Ecoturismo e do IV Encontro Interdisciplinar de Ecoturismo em Unidades de Conservação. São Paulo: Revista Brasileira de Ecoturismo, 4. pp. 575-575.

UNESCO - United Nations Educational, Scientific and Cultural Organization. Recuperado de http://www.unesco.org.

Valinhos, Prefeitura Municipal. Recuperado de www.valinhos.sp.gov.br.

Vinhedo, Prefeitura Municipal. Recuperado de http://www.vinhedo.sp.gov.br.

Artigo recebido em: 15/10/2012. Artigo aprovado em: 12/11/2012. 